\title{
Are women becoming extinct in the Computer Science and Informatics Program?
}

\author{
Gabriela Marín \\ Universidad de Costa Rica, Escuela de Ciencias de la Computación e Informática, \\ San Pedro, Costa Rica, 1626-2050 \\ gmarin@ecci.ucr.ac.cr \\ E. Gabriela Barrantes \\ Universidad de Costa Rica, Escuela de Ciencias de la Computación e Informática, \\ San Pedro, Costa Rica, 2060 \\ gbarrantes@ecci.ucr.ac.cr \\ Silvia Chavarría (†) ${ }^{1}$ \\ Universidad de Costa Rica, Posgrado en Computación e Informática, \\ San Pedro, Costa Rica, 1164-2350 \\ silviachava@yahoo.com
}

\begin{abstract}
In recent times a dramatically decreasing tendency in female participation in Computer Science has been documented around the world. When this occurs, it creates a series of problems that must be addressed. For the case of the undergraduate and graduate programs in Computer Science and Informatics at the Universidad de Costa Rica, we present evidence that (a) women are under-represented at both the undergraduate and graduate levels, and (b) the relative frequency of women in the undergraduate (but not graduate!) levels is effectively decreasing, and (c) women are more efficient at both graduating and getting admitted to graduate programs. Based on the available data, we confirm that the differences are not because of some inherent female deficiency but due to gender issues.
\end{abstract}

Keywords: Gender differences, Computer Science, participation, undergraduate program, graduate program

\footnotetext{
${ }^{1}$ Our friend and colleague, Silvia Chavarría passed away on April, 2008. We dedicate this posthumous paper to her, who was the main inspiration for this work.
} 


\section{Introduction}

Currently far less women than men are graduating from the undergraduate and graduate programs at the Escuela de Ciencias de la Computación e Informática (ECCI) (School of Computer Science and Informatics) from the Universidad de Costa Rica (UCR). As a consequence of this reality, a group of professors asked ourselves a series of questions. As a result of the present investigation, we have been able to answer some of those questios. Others are considered in [18], and some of them still remain:

- Is this a recent phenomenon or has it been happening for a long time?

- Are women less effective than men to graduate, that is, maybe many women start but we lose them along the way?

- Are young women reluctant to study Computer Science, and therefore we have fewer female candidates?

- Is the small number of women graduating from the undergraduate program affecting their decision to start graduate studies?

- What image do young people from both sexes about how is the Computer Science career and how is the workplace? Does this image affect their career choice?

- Do undergradute students and graduate students have the same opinions regarding their work perspectivesHow does the opinion about their work perspectives change between undergarduate and graduate students, many of which are already working?

- Is there a difference in perception among students regarding their competence to enroll in a Computer Science program?

- Is there any discrimination against women in computer-related fields, both during their studies as in the workplace? What effect could this discrimination have in the decision to study Computer Science?

- Are there gender differences in hiring expectations and expected benefits? Would this affect career choices?

We consider that diversity, among students and professors, is important in any universitary program. In the case of a more balanced gender participation in the Computer and Information field, we state that it is critical given that:

(1) This is a growing, unsaturated field with good salaries and professional prestige, and we wished that more women had access to it.

(2) The industry has complained in several occasions about the lack of CS professionals $[13,19]$, so by losing female candidates, we are losing a significant percentage of the prospective workforce.

(3) Women bring different perspectives that enhance the field $[2,13]$.

(4) It is desirable to avoid populations so minoritary that the norm of behavior becomes defined strictly by the majority [12].

We believe that the smaller participation of women in computer-related fields, and other technical and scientifical fields, is due to social, not biological factors. That is, we believe in a difference by gender, not by sex. In this artictle we will understand the term sex as the biological difference, and gender as a sociocultural categorization that implies social, educational, economical, political and occupational differences

We use Computer and Informatics (CI) to refer to all career and profession associated do develop and use efficiently computer technology, be it Information Systems, Information Technology, and so on. In this paper we will focus on the Bachelor Program in CI at the UCR, the ECCI (defined above). The UCR is the largest and most prestigious university in Costa Rica. The ECCI was founded in 1981 and currently graduates about one third of the CI professionals from public universities. Public Univerity graduates are coveted by the industry and there is practically no unemployment among our graduates (data provided by CAMTIC, the Costa-Rican association of IT industries, and yearly post-graduation interviews at ECCI). 
The study plan for the Bachelor degree at ECCI incorporates aspects from Computer Science, according to the ACM curriculum[1], as well as topics from Information Technologies (IT), like design and analysis of systems, software engineering, telecommunications engineering, and the impact of automatization in society.

The graduate program (Masters) in Computer and Informatics at the UCR was created as a continuation of the Bachelor program described before, and it is one of the most prestigious in the country. The program has two modalities: professional and academic. Most of the students (over 85\%) choose to follow the professional modality. The difference between both is that the students in the academc modality have to write and defend a thesis. The study program for the professional modality is composed of ten elective courses with their respective laboratories. Students have total freedom in choosing the courses among an offer of about 50 (although not all are available in any given semester). The population is relativeley homogeneous, with $80 \%$ of students coming from the Bachelors at ECCI, $15 \%$ coming from the undergraduate program in Computer Science (CS) at the Instituto Tecnológico de Costa Rica (ITCR), a program very similar to ours, and the remaining $5 \%$ come from other programs in CS or similar areas.

In this article we are going to review the status of the participation of the students, male and female, in the ECCI, both at the undergraduate as the graduate levels.

\section{Related Work}

For many years now many researchers, specially in the West, have studied and reported on the low female participation in computer-related fields in universities in several countries. Craig, Paradis y Turner (2002) [7] compare the situation in Australia, Great Britain, Hong Kong, and U.S.A. Other studies report on a single country, as follows (listed in alphabetical order by country): In Australia by Lewis, McKay, and Lang (2006) [17], and Clarke and Teague (1994) [9]; in Canada by Cukier (2003) [10]; in Israel by Vilner and Zur (2006) [22]; in Germany by Schelhowe (2006) [20]; in the U.S.A. by Klawe and Levenson (1995) [16], Hemenway (1995) [12], Beyer, Rynes, Perrault, Hay, and Haller (2003) [3], Joshi and Schmidt (2006) [14], Trauth, Quesenberry, and Morgan (2004)[21], and Katz, Allbritton, Aronis, Wilson, and Soffa (2006) [15]. Curiously Gharibyan and Gunsaulus (2006) [11] claim that in the Armenian Republic, one of the countries of the old Soviet Union, this phenomenon does not exist. However, they add that in the last years the proportion of females is decreasing as men displace them as they start finding this area more appealing.

Even though there is a low female participation in CI programs, the situation turns out to be even more critical: there have been reports of decreasing participation in the last years, for example in Australia (Lewis, McKay, and Lang (2006) [17]), and the U.S.A. ( Camp, (1997) [4]). This phenomenon has been called "shrinking pipeline". A similar phenomenon was reported in Costa Rica (Chavarría (1990) [6]).

The difference in male and female participation in CI is not only present within the academic world. The industry has detected significant differences in their workforce composition as well. A survey was carried out in 97companies in the IT sector as part of the Support Program for the Competitiveness of Software Development Sector in Costa Rica [19]; as a result a drastic imbalance in the composition by sex of the workforce at the professional level was reported. In large and medium companies, $82.3 \%$ of the employees are male, in small companies a $86.3 \%$, and in micro-enterprises a $92.6 \%$ [19]. In multiple industry-academy coordination meetings, the Chamber of Software Producers, CAPROSOFT, now called CAMTIC, has made public its concern about this situation. They see this inbalance as a threat, and at the same time as challenge to increase the human resources in the sector if it were possible to identify and solve the factors that inhibit women from entering CI programs.

\section{Female Participation in the Bachelors Program at the Escuela de Ciencias de la Computación e Informática}

In this section we study the relative participation of male and female students through time in the ECCI at the undergraduate level. 
As professors in the Program, we have always had the impression that the number of male students in our classes represent a crushing majority. However, we decided to carry on a detailed study to determine how small is the number of female students graduating from the program, and to determine if we also have a shrinking pipeline. In Figure 1 we can appreciate how the number of female graduates is relatively stable, while the number of male graduates is getting larger with an increasing rate throughout the years.

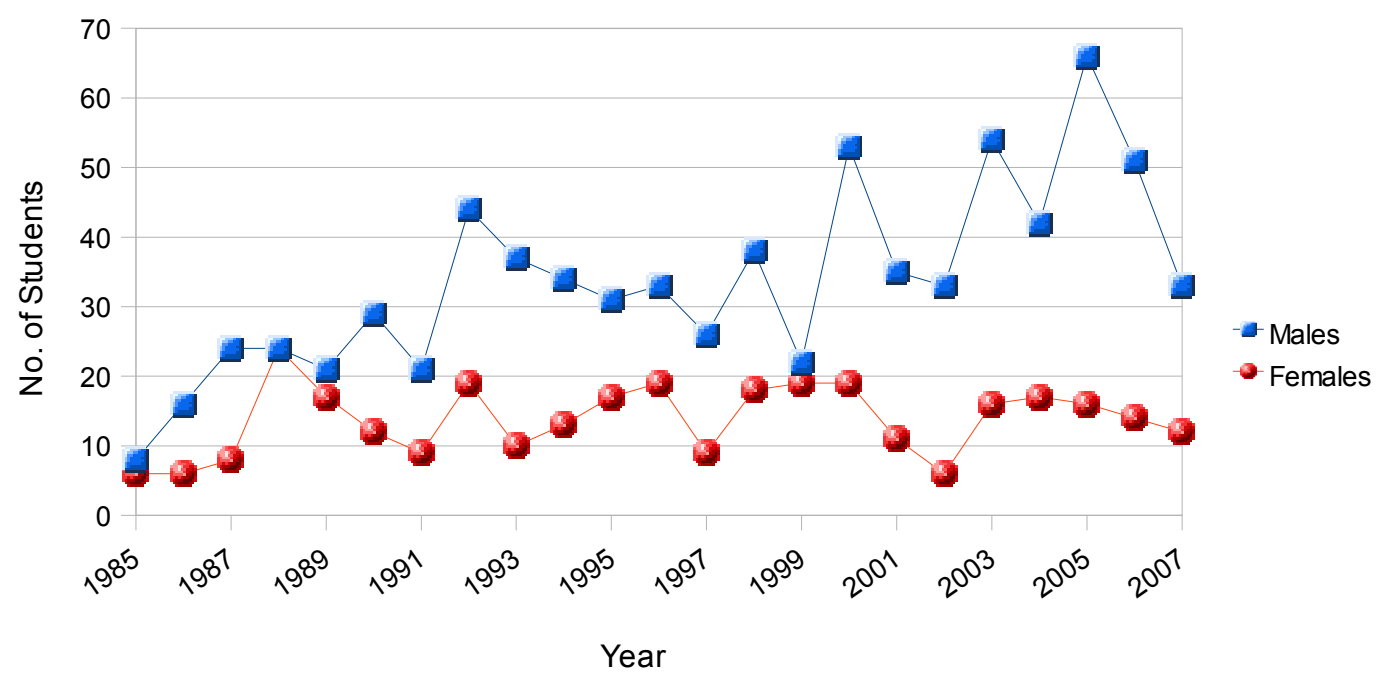

Figure 1. Number of graduates from the Bachelors Program at ECCI by sex and year. Graduate lists were obtained from the UCR Registrar's Office.

As it can be seen in Figure 1, the total number of graduates has increased, but the number of women has kept stable and low. A possible explanation, quite worrying actually, was that women starting the program were not graduating in the same proportion as the men, that is, we were loosing them on the way. Were this true, it might be due to women losing interest in a larger proportion than men, or because they were failing courses.

To test this hypothesis, we checked the sex distribution of students entering the program. In Figure 2, it can be clearly seen that the percentage of women entering is low. In the last 15 years, women accounted for just a $20.9 \%$ of the incoming students compared to a $79,1 \%$ of male students. Besides, their relative number has decreased from $30.4 \%$ in 1981 to $16.7 \%$ in 2007 . Notice the decreasing trend marked by the red line over Figure 2 .

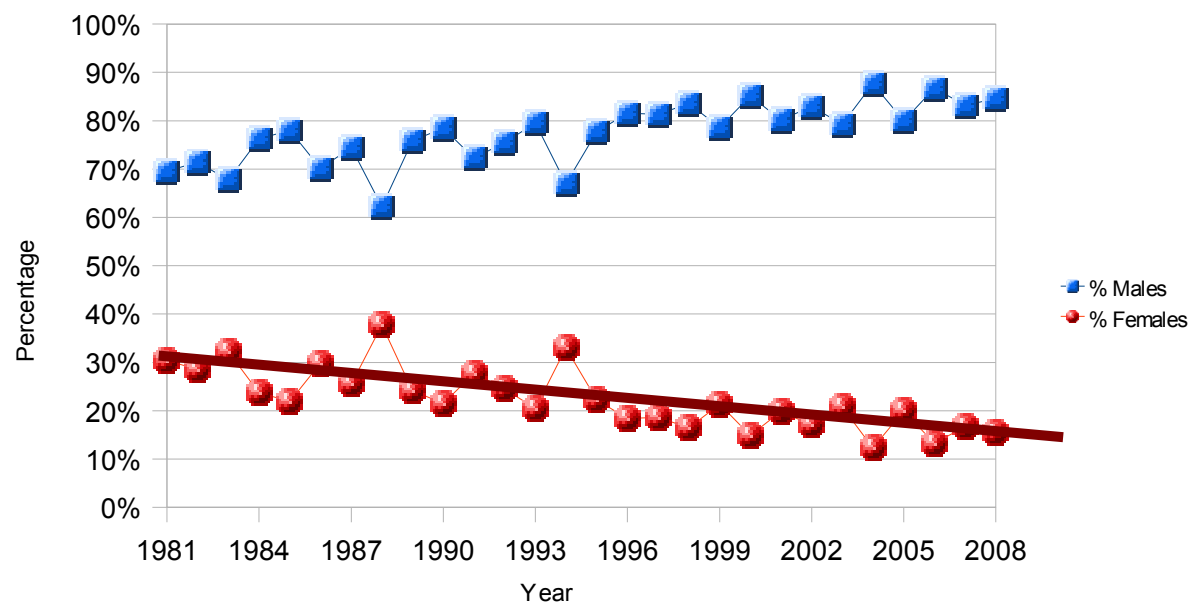

Figure 2. Percentage of studentes admitted to the Bachelors program at ECCI by sex and year. Lists of admitted students obtained from the Office of the Registrar at the UCR. 
The trend in decreasing admissions for women is fortunately not reflected as drastically at graduation, as it can be observed in Figure 3.

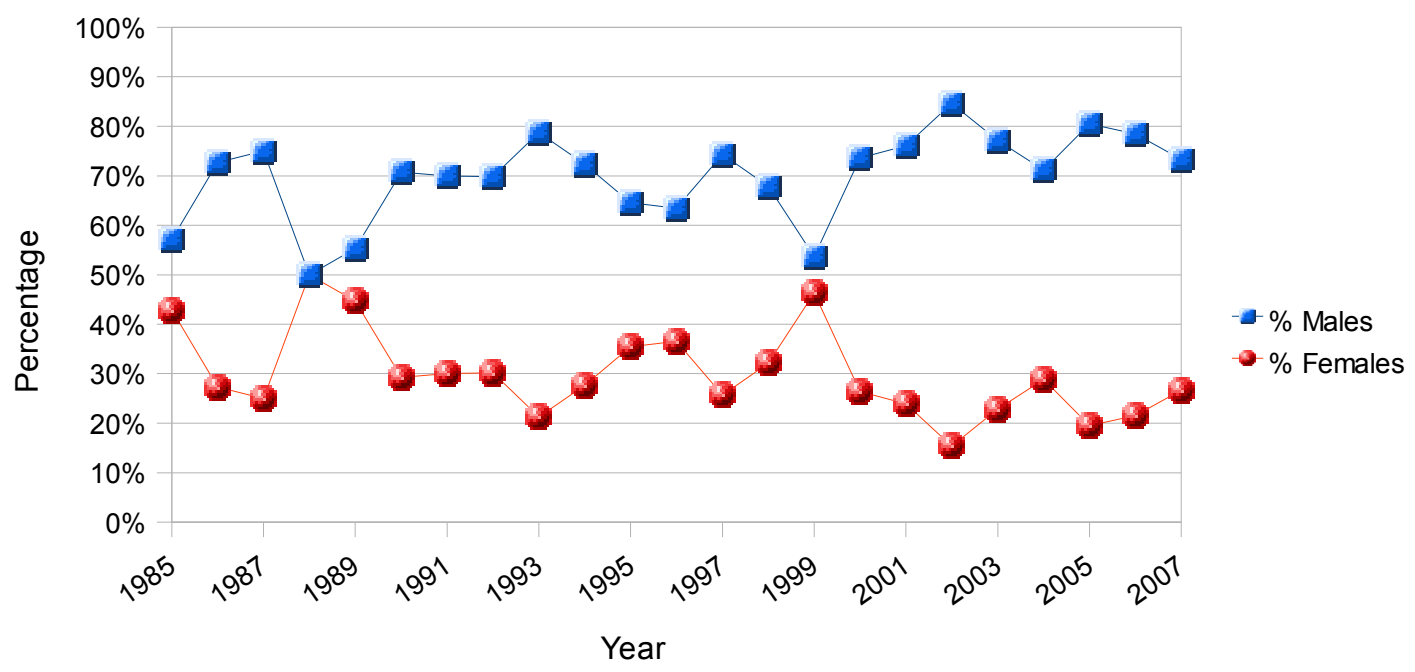

Figure 3. Percentage of graduates from the Bachelor's Program at ECCI by sex and year. Lists of graduating students obtained from the Office of the Registrar at the UCR.

It is interesting to point out that from the graduates of the last 15 years, a $70.8 \%$ have been men, and $29.2 \%$ women, but at admission, just $20.9 \%$ were female. This is an early indication that women are not being inefficient at graduating. We pursued this issue further. Figures 4 and 5 are used to compare the percentage of graduates by sex according its cohort. To build these figures, the relative population of admitted men and women is compared with the relative population of graduates after four years (in Figure 4) and five years (in Figure 5). Both possibilities are presented because even if the study plan stipulates a duration of four years, many of our students take five or more years to graduate.

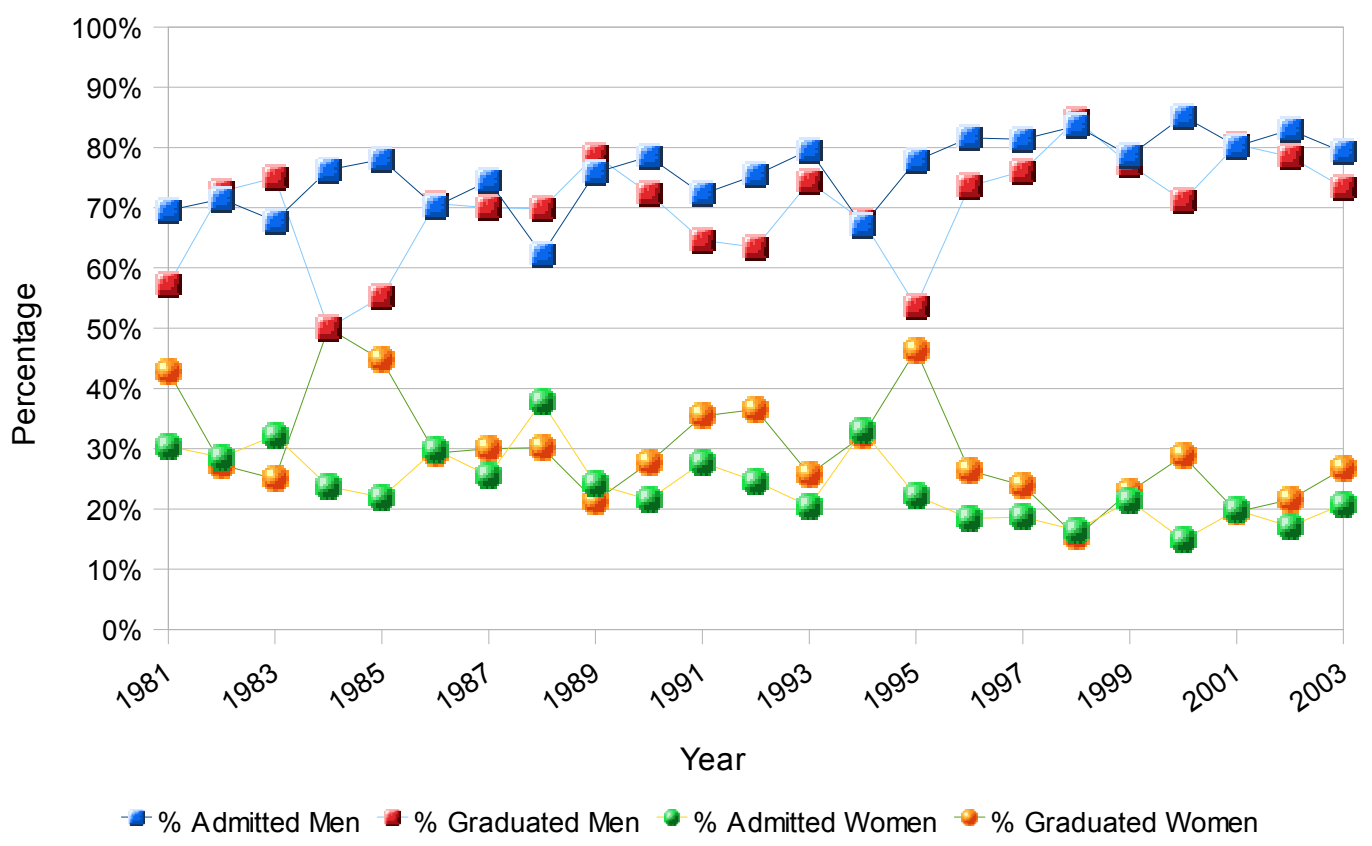

Figure 4. Comparison of the admission percentages (at admission year) and graduation (four years after the admission) for the Bachelors program at ECCI, by sex and year. Lists of admitted and graduated students obtained from the Office of the Registrar at the UCR. 


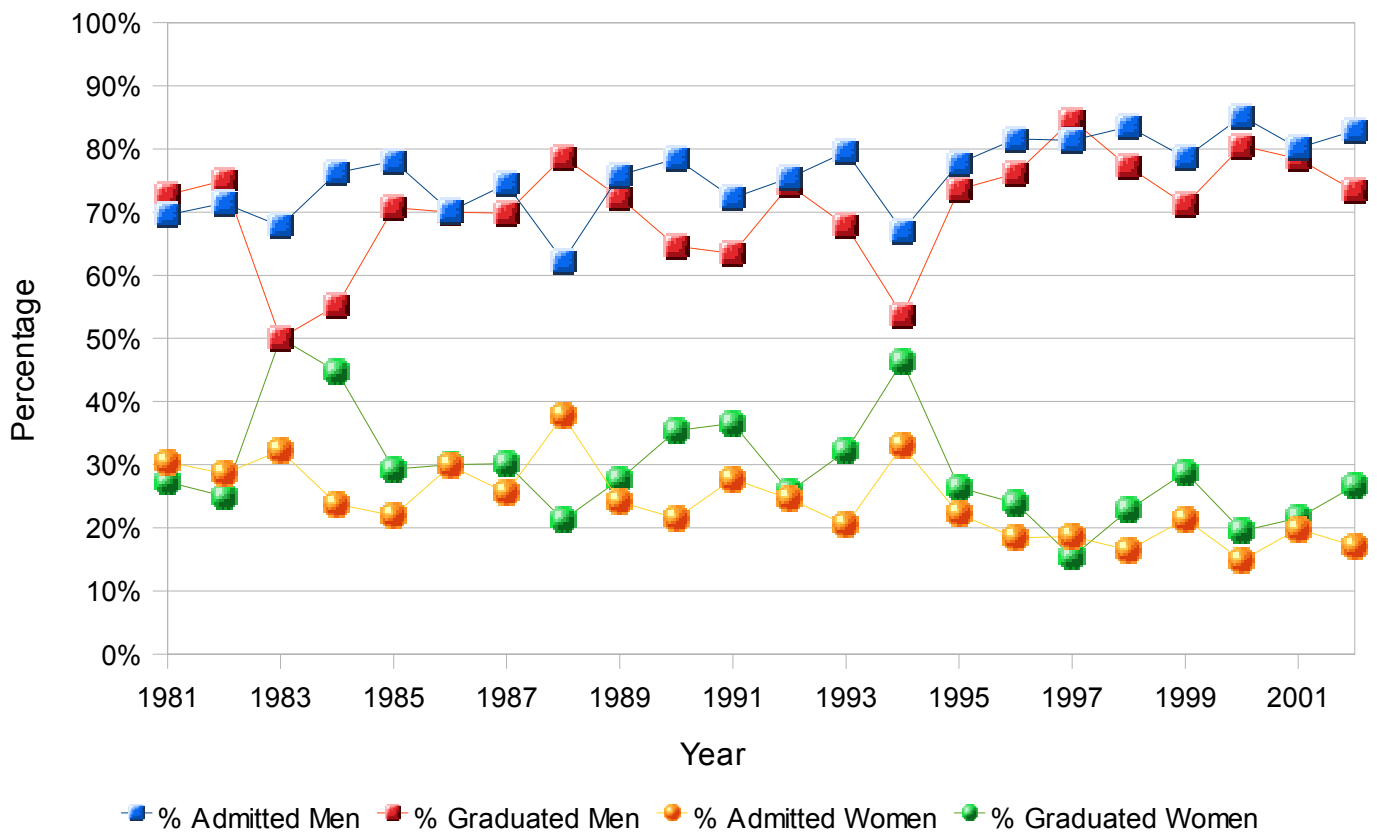

Figure 5. Comparison of the admission percentages (at admission year) and graduation (five years after the admission) for the Bachelors program at ECCI, by sex and year. Lists of admitted and graduated students obtained from the Office of the Registrar at the UCR.

From figures 5 and 6 we can see clearly that we were wrong about the hypothesis that women are less efficient at graduating. Actually, we end up having the opposite phenomenon of what we had initially: in the case of men, the percentage of graduates tends to be lower than the percentage of admitted students; whereas for women, the percentage of graduates tends to be much higher than the percentage of admissions. It would be interesting to see if there are other studies that show similar findings.

\section{Presence of women at the Masters Program at ECCI}

We were also interested in investigating what was happening to women in the graduate program offered by the ECCI, the Masters in Computer and Information. There are few studies about women in CI graduate programs, except maybe in the U.S.A., as reported by Cohoon (2007) [8].

We investigated the participation of women in the professional modality, at the Central Campus of UCR. We decided not to report results for the program in other campuses, nor the academic modality because the number of students in them is too small to detect any patterns.

The analysis for the Masters Program included not only the students that were admitted and who graduated, but it was widened to include the requests for admission as well. It was not possible to do the same for the undergraduate program because the Office of the Registrar does not store complete information about requests for admisión, which made the determination of percentages by sex impossible. This is alarming because it is known that when data is not stored segregated by sex, the gender problematic is made invisible. Chavarría (1997) [5] reviews data for four years when this data was known, and concludes that the participation difference for women cannot be explained as a consequence of the admission process, but by the low number of women that request admission.

From the admitted population in the last 7 years, a $76.6 \%$ has been male and a $23.4 \%$ female (slightly better than the historical $20.9 \%$ admission percentage at the undergraduate program). It must be pointed out that women are a minority of the population that can request admittance to the program, given that they must 
have at least a Bachelor degree in CI or a related program to begin with. However, in Figure 6, examining the vertical distance between the requesting and admitted populations, an interesting phenomenon can be seen: women are more effective than men at the admission process (a larger percentage of women than men is admitted relative to the requests).

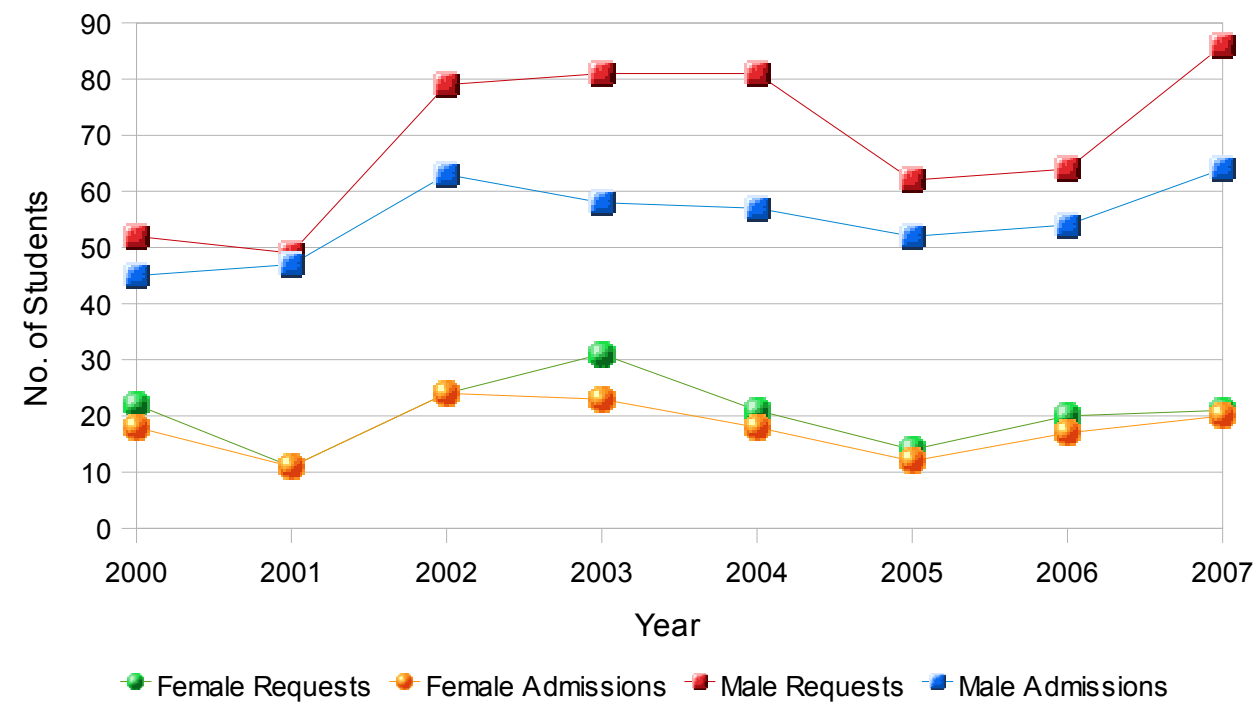

Figure 6. Number of requesting and admitted students to the professional modality at the Masters in CI program at ECCI. Data obtained from the Masters Program Administrative Office.

In terms of the relative participation of males and females in the admission process, it can be seen in Figure 7 that there is no shrinking pipeline in the graduate program. This is a disconcerting phenomenon, given that the majority of its students come from the CI Bachelors program in which the shrinking is happening (see Figure 3).

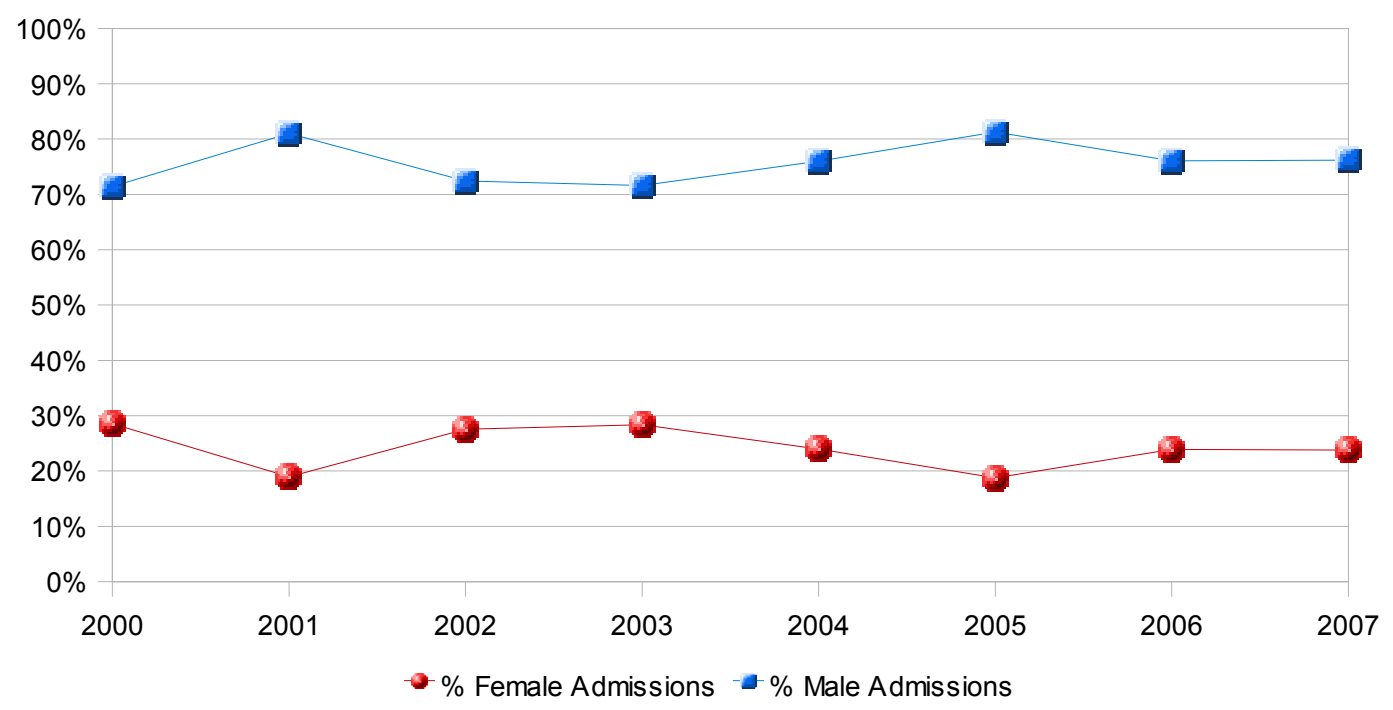

Figure 7. Percentage of admitted students to the professional modality at the Master in CI program at ECCI. Data obtained from the Masters Program Administrative Office. 
A partial explanation for this situation can be found in Figure 8, where it is shown that the rates of admitted to requesting women are larger than the same rates for men, that is, women are more successful at gaining entrance to the Masters Program.

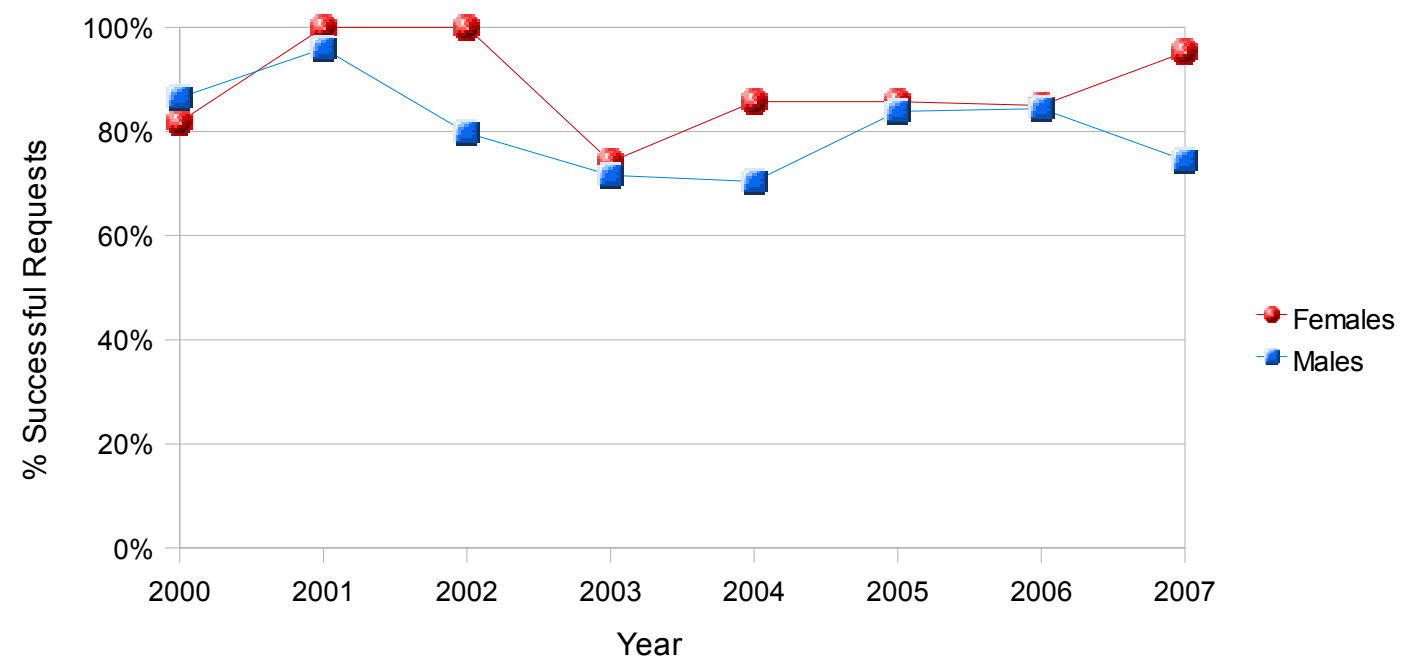

Figure 8. Percentage of success at gaining admission to the Masters Program (Professional Modality) by sex. Shown are the rates of admitted to requesting students (in percentages). Data obtained from the Masters Program Administrative Office.

The percentage of graduating men and women in the Masters Program is shown in Figure 9. When reviewing how successful were the women in the Program in terms of graduation, we found that, contrary to what happens in the undergraduate program, the overall percentage of graduating with respect to admitted women is lower ( $23 \%$ graduating vs $25 \%$ admitted). The difference is not statistically significant however. Once admitted, it seems that desertion and outright failure for graduate students is relatively balanced among males and females.

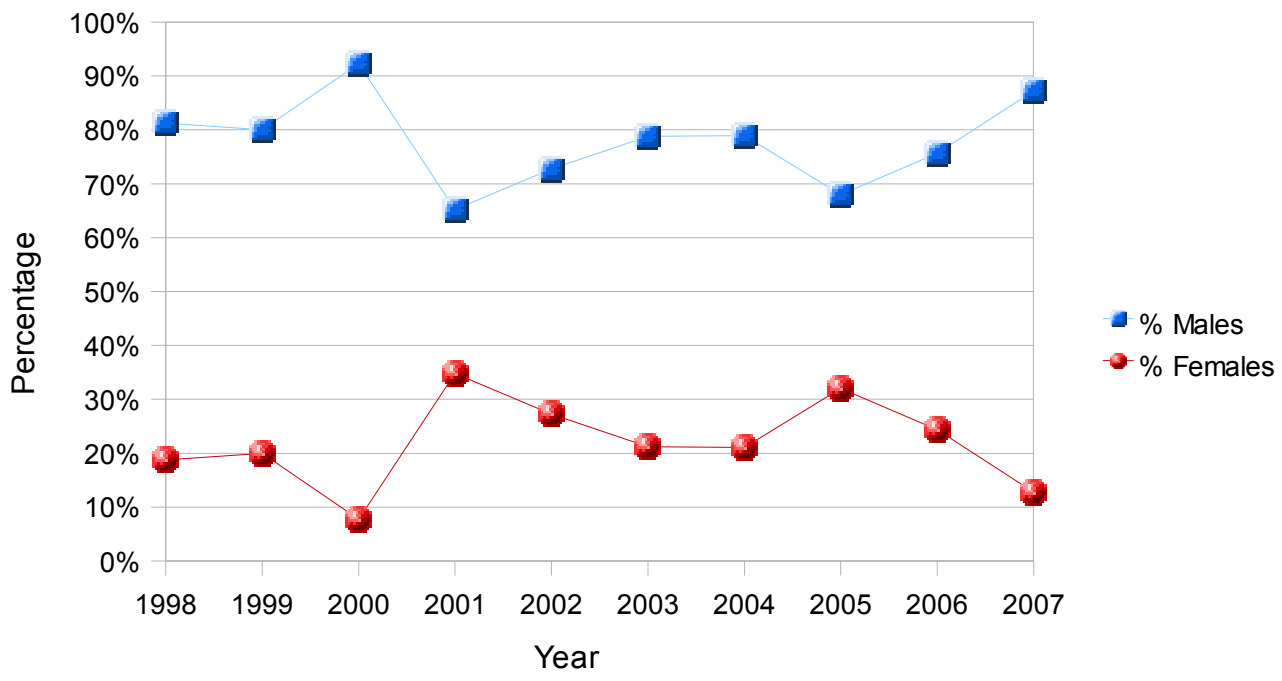

Figure 9. Percentage of graduation at the Masters Program (Professional Modality) by sex. Data obtained from the Masters Program Administrative Office. 
After studying the female and male populations in the undergaduate and graduate programs at ECCI, it seems that women do not have further difficulties to be successful in our field and even have a slightly better performance than men. In the undergraduate program, typically there is at least one woman among the three best grade point averages ( 1 out of 3 against a 1 to 5 proportion in the admission population). In the graduate program, women graduate slightly faster in average, and with a slightly higher grade average (the difference is not statistically significant, however.)

\section{Conclusions}

This study confirms the difference in participation of women both in the undergraduate and the graduate programs in CI at the UCR. The admission of women to the undergraduate program at ECCI shows a decreasing trend in participation. This phenomenon is not present in the graduate program, where themale to female rate varies very little.

This research shows that women, in relation to the source population, request admission to the Masters Program in a larger proportion. Even more, the rate of admitted to requesting women is larger than that of men, which shows that they are more efficient in the admission process.

Women are more effective graduating from the Bachelors Program and as effective as men at the Masters level. In the undergraduate program the proportion of women graduating is much larger than the proportion of women admitted.

We show that the difference in the number of women graduating at the Bachelor and Masters Programs at ECCI does not result from any difficulties in finishing the course of studies, either by desertion or course failure. The difference is generated by the low number of women that are admitted. In the case of the graduate program, the main reason of the difference is the small size of the elegible population (women that graduated from the undergraduate program). We recommend that the factors that lead to the small number of women applying to the undergraduate program should be investigated further.

Additionally, the effectiveness of women at graduating confirms that there is not an inherently female deficiency to be successful at CI programs, that it is a gender issue.

Neither us nor the researchers in other countries believe that there is a single strategy to solve the problem; however, we are sure that informing and making this phenomenon public is the first step to look for solutions. 


\section{References}

[1] ACM. Computing Curricula 2001. Journal of Educational Resources in Computing, 1, 3(Fall 2001). ACM Press, New York, NY.

[2] Beyer, S., DeKeuster, M., Walter, K., Colar, M., and Holcomb, C. Changes in CS students' attitudes towards CS over time: an examination of gender differences. In Proceedings of the 36th SIGCSE Technical Symposium on Computer Science Education. St. Louis, Missouri, USA (February, 2005). SIGCSE '05. ACM Press, New York, NY, 392-396.

[3] Beyer, S., Rynes, K., Perrault, J., Hay, K., and Haller, S. 2003. Gender differences in computer science students. In Proceedings of the 34th SIGCSE Technical Symposium on Computer Science Education (Reno, Navada, USA, February 19 - 23, 2003). SIGCSE '03. ACM Press, New York, NY, 49-53.

[4] Camp, T. The incredible shrinking pipeline. Communications of the ACM 40, 10 (1997), 103-110.

[5] Chavarría, S. Hacia cursos introductorios más incluyentes para las mujeres en la carrera de ciencias de la computación. En Memorias de la Segunda Conferencia Latino-Americana de Facultades y Escuelas de Ingeniería de Sistemas y Ciencias de la Computación. Santiago, Chile (1997).

[6] Chavarría, S. Women's choice of careers at the University. In Proceedings of the European and Third World GASAT Conference. Jonkoping, Sweden. (1990).

[7] Craig, A, Paradis, R., and Turner, E. A Gendered View of Computer Professionals: Preliminary Results of a Survey. ACM SIGCSE Bulletin 34, 2 (Jun. 2002). 101-104.

[8] Cohoon, J. M. Gendered experiences of computing graduate programs. In Proceedings of the 38th SIGCSE Technical Symposium on Computer Science Education (March , 2007). ACM Press, New York, NY, 546-550.

[9] Clarke, V. A. and Teague, G. J. A psychological perspective on gender differences in computing participation. In Proceedings of the Twenty-Fifth SIGCSE Symposium on Computer Science Education. Phoenix, Arizona, United States, (1994). ACM Press, New York, NY, 258-262.

[10] Cukier, W. Constructing the IT skills shortage in Canada: the implications of institutional discourse and practices for the participation of women. In Proceedings of the 2003 SIGMIS Conference on Computer Personnel Research: Freedom in Philadelphia--Leveraging Differences and Diversity in the IT Workforce. Philadelphia, Pennsylvania (April , 2003), ACM Press, New York, NY, 24-33.

[11] Gharibyan, H. and Gunsaulus, S. Gender gap in computer science does not exist in one former soviet republic: results of a study. In Proceedings of the 11th Annual SIGCSE Conference on innovation and Technology in Computer Science Education. Bologna, Italy (June, 2006). ITICSE '06. ACM Press, New York, NY, 222-226.

[12] Hemenway, K. Human nature and the glass ceiling in industry. Communications of the ACM 38, 1 (Jan. 1995), 55-62.

[13] Joshi, K. D. and Kuhn, K. Gender differences in IS career choice: examine the role of attitudes and social norms in selecting IS profession. In Proceedings of the 2001 ACM SIGCPR Conference on Computer Personnel Research. San Diego, California, United States (2001). M. Serva, Ed. SIGCPR '01. ACM Press, New York, NY, 121-124.

[14] Joshi, K. D. and Schmidt, N. L. Is the information systems profession gendered?: characterization of IS professionals and IS career. SIGMIS Database 37, 4 (Nov. 2006), 26-41.

[15] Katz, S., Allbritton, D., Aronis, J., Wilson, C., and Soffa, M. L. Gender, achievement, and persistence in an undergraduate computer science program. SIGMIS Database 37, 4 (Nov. 2006), 42-57.

[16] Klawe, M. and Leveson, N. 1995. Women in computing: where are we now? Communications of the ACM 38, 1 (Jan. 1995), 29-35.

[17] Lewis, S., McKay, J., and Lang, C. The next wave of gender projects in IT curriculum teaching at universities. In Proceedings of the 8th Austalian Conference on Computing Education - Volume 52. 
Hobart, Australia (January 16 - 19, 2006). D. Tolhurst and S. Mann, Eds. ACM International Conference Proceeding Series, vol. 165. Australian Computer Society, Darlinghurst, Australia, 135-142.

[18] Marín, G., Barrantes, E.G., and Chavarría, S. Diferencias de percepción sobre Computación e Informática debidas a género y experiencia. Proceedings of the Conferencia Latinoamericana de Informática,CLEI 2007, San José, Costa Rica, 2007.

[19] Mata, F. and Jofré, A. Informe Final del Estudio de Oferta y Demanda del Recurso Humano, Programa de apoyo a la competitividad del sector de desarrollo de software en Costa Rica, San José, Costa Rica, 2001.

[20] Schelhowe, H. Gender questions and computing science. In Proceedings of the international Symposium on Women and Ict: Creating Global Transformation. Baltimore, Maryland (June, 2005). C. Morrell and J. Sanders, Eds. CWIT '05, vol. 126. ACM Press, New York, NY, 10.

[21] Trauth, E. M., Quesenberry, J. L., and Morgan, A. J. 2004. Understanding the under representation of women in IT: toward a theory of individual differences. In Proceedings of the 2004 SIGMIS Conference on Computer Personnel Research: Careers, Culture, and Ethics in A Networked Environment (Tucson, AZ, USA, April 22 - 24, 2004). SIGMIS CPR '04. ACM Press, New York, NY, 114-119.

[22] Vilner, T. and Zur, E. Once she makes it, she is there: gender differences in computer science study. In Proceedings of the 11th Annual SIGCSE Conference on innovation and Technology in Computer Science Education. Bologna, Italy. (June, 2006). ITICSE '06. ACM Press, New York, NY, 227-231. 